\title{
Produção e Fluxo de Metano na Floresta Nacional do Tapajós
}

\author{
Alirio Tenório Furtado Neto ${ }^{1}$ (D), José Mauro Sousa de Moura ${ }^{1}$ (D), Rodrigo da Silva ${ }^{1}$ (D), \\ Raimundo Cosme de Oliveira Junior ${ }^{2}$ (D), Luciana Vanni Gatti ${ }^{3}$ (D), Thomas Röckmann ${ }^{4}$ (D) \\ ${ }^{1}$ Universidade Federal do Oeste do Pará, Santarém, PA, Brasil. \\ ${ }^{2}$ Embrapa Amazônia Oriental, Empresa Brasileira de Pesquisa Agropecuária, \\ Santarém, PA, Brasil. \\ ${ }^{3}$ Centro de Ciências do Sistema Terrestre, Instituto Nacional de Pesquisas Espaciais, \\ São José dos Campos, SP, Brasil. \\ ${ }^{4}$ Universidade de Utrecht, Utrecht, Netherlands.
}

Recebido em: 15 de Fevereiro de 2016 - Aceito em: 12 de Julho de 2019

\begin{abstract}
Resumo
O metano é o segundo gás de efeito estufa e sua concentração na atmosfera aumentou $259 \%$ desde 1750 . A média global da fração molar de $\mathrm{CH}_{4}$ atingiu um novo recorde de $1813 \pm 2$ ppb em 2011. Este trabalho objetiva quantificar a concentração e fluxo de metano no perfil vertical da floresta primária tropical (Floresta Nacional do Tapajós), assim como, determinar a emissão de metano na interface solo-atmosfera durante o período chuvoso e de estiagem para o ano de 2012. Amostras de ar foram coletadas in situ diretamente do solo através do uso de câmaras estáticas e no perfil vertical da floresta em três alturas diferentes $(2 \mathrm{~m}, 16 \mathrm{~m}$ e $36 \mathrm{~m})$ e acima da copa $(63 \mathrm{~m})$ através do uso da torre micrometeorológica de $65 \mathrm{~m}$. Posteriormente, as amostras de ar foram analisadas por cromatografia gasosa. A concentração de metano na estratificação vertical da vegetação foi de $1,866 \pm 0,038 \mathrm{ppm}$ e o fluxo foi $\sim 15,50 \mathrm{mg} \mathrm{de} \mathrm{CH}_{4} \cdot \mathrm{m}^{-2} \mathrm{~d}^{-1}$ e a

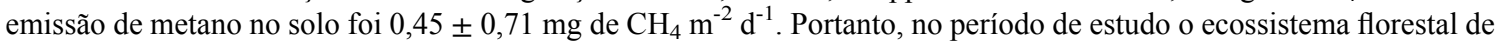
terra-firme atuou como fonte de $\mathrm{CH}_{4}$ para atmosfera.
\end{abstract}

Palavras-chave: ciclo biogeoquímico, ecossistema florestal, emissão de metano.

\section{Production and Flux of Methane in the Tapajós National Forest}

\begin{abstract}
Methane is the second most powerful greenhouse gas and its concentration in the atmosphere has increased $259 \%$ since 1750. The overall average of the molar fraction of $\mathrm{CH}_{4}$ reached a new record of $1813 \pm 2 \mathrm{ppb}$ in 2011 . This study aims to quantify the concentration and flux of methane in the vertical profile of a tropical primary forest (Tapajós National Forest), as well as to determine the emission of methane in the air-soil interface during the rainy season and the dry season for the year 2012. Air samples were collected at the air-soil, interface using static chambers and throughout the vertical profile of the forest at three different heights $(2 \mathrm{~m}, 16 \mathrm{~m}$, and $36 \mathrm{~m})$ and at above the canopy $(63 \mathrm{~m})$ accessed by a $65 \mathrm{~m}$ micrometeorological tower. Subsequently, the air samples were analyzed by gas chromatography. The concentration of methane in the vertical stratification of the vegetation was $1.866 \pm 0,038 \mathrm{ppm}$ and the flux was $\sim 15.50 \mathrm{mg}$ de $\mathrm{CH}_{4} \cdot \mathrm{m}^{-2} \mathrm{~d}^{-1}$ and the emission of methane the soil was $0.45 \pm 0,71 \mathrm{mg} \mathrm{CH} \mathrm{CH}_{4} \cdot \mathrm{m}^{-2} \mathrm{~d}^{-1}$. Therefore, for the period of study, the ecosystem of upland forest acted as a source of $\mathrm{CH}_{4}$ to the atmosphere.
\end{abstract}

Keywords: biogeochemical cycle, forest ecosystem, methane emission.

\section{Introdução}

$\mathrm{O}$ metano $\left(\mathrm{CH}_{4}\right)$ é o segundo gás de efeito estufa mais importante e sua concentração aumentou $259 \%$ desde 1750 ( 700 ppb). Em 2011, a média global da fração molar de $\mathrm{CH}_{4}$ atingiu um novo recorde de $1813 \pm 2$ ppb um aumento de 5 ppb em relação ao ano de 2010 e nos

Autor de correspondência: Alirio Tenório Furtado Neto, furtadoufpa@yahoo.com.br. 
últimos 10 anos obteve um acréscimo de 3,2 ppb.ano ${ }^{-1}$. No

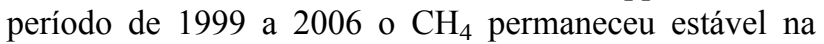
atmosfera e a partir de 2007 voltou a crescer a uma taxa de 5 ppb.ano ${ }^{-1}$ (WMO, 2012). Esse gás é um forte absorvedor de luz infravermelha na região espectral de 7,66 $\mu \mathrm{m}$, de acordo com Dickinson e Cicerone (1986), por isso, o potencial de aquecimento do $\mathrm{CH}_{4}$ na atmosfera é alto, sendo 21 vezes maior que o $\mathrm{CO}_{2}$ para um cenário de 100 anos e sua forçante radiativa de $48 \mathrm{~W} \cdot \mathrm{m}^{-2}$ representa aproximadamente $18 \%$ (Esta percentagem é calculada como a contribuição relativa do gás mencionado para o aumento da radiação de escala global provocada por todos os gases de efeito estufa de vida longa desde 1750) da média total global dos gases de efeito estufa de vida longa. A durabilidade do $\mathrm{CH}_{4}$ na atmosfera é estimada em 12 anos (IPCC, 2007).

As fontes de $\mathrm{CH}_{4}$ da biosfera para a atmosfera foram sempre atribuídas aos processos microbianos anaeróbicos em solos úmidos, áreas inundadas, cultivos de arroz, intestinos de cupins e ruminantes, decomposições de dejetos humanos e agrícolas, queimas de biomassas, mineração de combustíveis fósseis e a fontes geológicas incluindo as erupções vulcânicas.

Medidas realizadas em níveis regionais por Frankenberg et al. (2005) usando dados de satélite da Agência Espacial Europeia constataram que as concentrações de $\mathrm{CH}_{4}$ para as florestas tropicais foram maiores do que o esperado, os mesmos atribuíram a fontes já conhecidas como as zonas úmidas, queimas de biomassas, cupins, gados e também incluíram uma fonte de $\mathrm{CH}_{4}$ até então desconhecida podendo está diretamente relacionada as florestas tropicais.

Bergamaschi et al. (2007) e Schneising et al. (2009) também detectaram uma emissão significativa em florestas tropicais a partir das observações por satélite. Frankenberg et al. (2008) retrabalharam seus dados de $\mathrm{CH}_{4}$, pois suas medidas para as florestas tropicais poderiam ser influenciadas pela interferência de espectroscopia do vapor d'água, mesmo assim, ainda obtiveram uma emissão substancial de $\mathrm{CH}_{4}$ das florestas tropicais.

Miller et al. (2007) também realizaram medidas regionais, mas com metodologia diferente da supracitada, pois, coletaram amostras de ar em frascos para análise da concentração de $\mathrm{CH}_{4}$ utilizando uma aeronave que sobrevoava (perfil vertical) a uma altitude de 300 a $4300 \mathrm{~m}$ acima do nível do mar em dois sítios localizados na Amazônia Oriental e Central. Os cálculos para emissão de $\mathrm{CH}_{4}$ nestas florestas apresentaram média de $27 \mathrm{mg} \mathrm{de} \mathrm{CH}_{4} \mathrm{~m}^{-2}$ $\mathrm{dia}^{-1}$, entretanto, não souberam interpretar seus dados de forma a explicar as possíveis fontes, pois poderia estar relacionada a diversos fatores, dentre eles, a emissão de $4 \mathrm{mg}$ de $\mathrm{CH}_{4} \mathrm{~m}^{-2}$ dia $^{-1}$ das plantas, segundo Keller et al. (2006) e aproximadamente uma média de $7 \mathrm{mg} \mathrm{de} \mathrm{CH}_{4} \mathrm{~m}^{-2}$ dia $^{-1}$ de emissão desconhecidas no período noturno (Carmo et al. 2006).
Carmo et al. (2006) usando medidas locais diretas da concentração de $\mathrm{CH}_{4}$ em perfis verticais de florestas de terra-firme da Amazônia e medidas de fluxo de $\mathrm{CO}_{2}$ do solo, estimaram que a emissão líquida de $\mathrm{CH}_{4}$ varia entre 2 e $21 \mathrm{mg} \mathrm{CH}_{4} \mathrm{~m}^{-2} \mathrm{dia}^{-1}$, apresentando uma estimativa de emissão anual variando de 4 e $38 \mathrm{Tg} \mathrm{CH}_{4}$ ano $^{-1}$.

Observações experimentais realizadas em laboratórios por Keppler et al. (2006) verificaram a produção efetiva de $\mathrm{CH}_{4}$ sob condições aeróbicas a partir de folhas vivas e mortas, estimando uma emissão global entre $62 \mathrm{e}$ $236 \mathrm{Tg}$ de $\mathrm{CH}_{4}$ ano ${ }^{-1}$ a partir de plantas vivas e $0,5 \mathrm{a}$ 6,6 $\mathrm{Tg}$ de $\mathrm{CH}_{4}$ ano ${ }^{-1}$ a partir de plantas mortas. Além disso, pesquisas realizadas por Vigano et al. (2008) mostraram o efeito da radiação UV e da temperatura elevada na emissão de $\mathrm{CH}_{4}$ em folhas secas e frescas de mais de 20 espécies de plantas e de componentes estruturais incluindo a pectina, lignina e celulose. Eles demostraram que a emissão de $\mathrm{CH}_{4}$ aumenta em função da irradiância UV indicando um processo fotoquímico direto. Outros pesquisadores como McLeod et al. (2008); Bruhn et al. (2009) também observaram que as emissões de $\mathrm{CH}_{4}$ eram estimuladas pela radiação UV.

Qaderi e Reid (2009) relataram o efeito da temperatura, da radiação UV-B e do estresse hídrico na emissão de $\mathrm{CH}_{4}$. A diferença com relação aos estudos citados anteriormente foi que os raios UV influenciavam na emissão de $\mathrm{CH}_{4}$ da planta após a interrupção do estresse hídrico. Portanto, observaram que a irradiação UV, a temperatura elevada poderia conduzir a formação de $\mathrm{CH}_{4}$ na planta, na folhagem, e nos componentes estruturais das plantas.

Estes fatores podem explicar as discrepâncias observadas nas emissões de $\mathrm{CH}_{4}$ oriundas em áreas de florestas tropicais. Entretanto, Querino et al. (2011) verificaram o fluxo turbulento e o gradiente vertical da razão de mistura do $\mathrm{CH}_{4}$ em florestas de terra firme localizada na Reserva Biológica de Cuieiras (aproximadamente $60 \mathrm{Km}$ ao Norte de Manaus, Brasil). Eles observaram um gradiente continuo de $\mathrm{CH}_{4}$ no interior da copa originado da superfície, no entanto, não há evidência clara da emissão de $\mathrm{CH}_{4}$ aeróbico.

Pesquisas realizadas por meio da técnica de covariância de vórtices turbulentos (Eddy Covariance) mostraram que as florestas tropicais da Amazônia apresentavam valores altos de concentração de $\mathrm{CH}_{4}$ durante $\mathrm{o}$ período noturno. Este aumento na concentração de $\mathrm{CH}_{4} \mathrm{e}$ $\mathrm{CO}_{2}$ no perfil vertical da floresta, durante as estações seca e chuvosa, fortaleceram a hipótese de que durante a noite, ocorreria a produção de metano em microsítios anaeróbios, e que este se acumularia nos compartimentos do dossel da floresta e/ou emissões noturnas ainda desconhecidas (Wofsk et al. 1988; Kuck et al. 2000; Martens et al. 2004; Carmo et al. 2006; Querino et al. 2011).

Estes microsítios anaeróbicos podem estar associados às altas taxas de precipitações, temperaturas elevadas e os altos índices de umidades relativas do ar, que chegam 
a $100 \%$ mesmo nos períodos de seca, proporcionam a condensação de vapor d'água no interior da floresta durante a noite. Na floresta Nacional do Tapajós, por exemplo, a ocorrência de várias espécies de bromélias e árvores cujos troncos possibilitam o armazenamento de água podem fornecer condições de anaerobiose e assim permitir a decomposição de matéria orgânica e consequentemente a produção de metano (Parotta et al. 1995).

Estudos para verificar o balanço regional de $\mathrm{CH}_{4}$ ainda são realizados com baixa intensidade na Amazônia e com precisões duvidosas. Deste modo, conhecer a produção e o fluxo desse gás para atmosfera na região é de grande importância na avaliação da dinâmica do carbono neste ecossistema para melhor entendimento de seu ciclo biogeoquímico.

O principal objetivo deste trabalho foi quantificar a concentração e o fluxo de $\mathrm{CH}_{4}$ no perfil vertical da floresta, assim como, determinar a emissão desse gás na interface solo-atmosfera em uma área de floresta de terra firme na FLONA Tapajós. Além disso, procurou-se definir a variabilidade sazonal da concentração e do fluxo do gás neste ecossistema, além disso, verificar a influência de fatores ambientais (umidade e temperatura do solo) atuando diretamente no comportamento do metano.

\section{Material e Métodos}

\subsection{Descrição da área de estudo}

A Floresta Nacional do Tapajós (FNT) está localizada no Estado do Pará, Brasil e atualmente está sob a jurisdição do ICMBio (Instituto Chico Mendes de Conservação da Biodiversidade), foi criada pelo decreto $\mathrm{n}^{\circ}$ 73.683 de fevereiro de 1974, e alterada pela Lei Federal $n^{\circ}$ 12.678 de junho de 2012 a qual diminui sua área de 600.000 para 527.319 hectares. Esta unidade federal tem como objetivo básico o uso múltiplo sustentável dos recursos florestais e a pesquisa científica, por isso, a FNT é classificada como uma unidade de conservação de uso sustentável.

A área de estudo compreende a região pertencente ao município de Belterra - PA, a $67 \mathrm{~km}$ da cidade de Santarém ao longo da BR 163. O local dispõe de uma torre metálica de $65 \mathrm{~m}$ (S 0251'18,4”' e W 5457’32,7’) a qual é utilizada para coleta de dados micrometeorológicos pertencente ao projeto de experimento de Grande - Escala da Biosfera - Atmosfera na Amazônia (LBA) administrada pelo escritório regional do LBA em Santarém - PA. Essa torre permite o acesso ao dossel da floresta.

O clima da região, segundo a classificação de Köppen é do tipo Ami (clima megatérmico, tropical úmido), sendo a temperatura média do mês mais frio acima de $18{ }^{\circ} \mathrm{C}$, também apresenta uma temperatura média anual em torno de $24,8{ }^{\circ} \mathrm{C}$, umidade relativa do ar em média
$90 \%$ e precipitação média anual de $2100 \mathrm{~mm}$ (Pereira et al. 2002; Costa et al. 2008).

É importante lembrar que, a vegetação predominante no entorno da torre usada para as coletas de ar, localiza-se no alto platô, também chamada de floresta de terra-firme, do tipo ombrófila densa (de baixas altitudes e/ou submontana), composta por árvores com altura do dossel variando entre 30-35 m e algumas árvores alcançando 40$45 \mathrm{~m}$ (Moura, 2010).

Nesta região ocorre a predominância de LATOSSOLO AMARELO Distrófico, caracterizado por diferentes texturas, com predomínio de argila principalmente nas áreas de platô onde as torres estão localizadas (Silver et al. 2000; Nepstad et al. 2002; Telles et al. 2004).

\subsection{Regime pluviométrico}

A precipitação média anual para o ano de 2012 na região da FNT foi de 1539,2 mm, valor obtido pela estação Meteorológica de Observação de Superfície do INMET, sendo a estação seca (menos de $100 \mathrm{~mm}$ por mês) no mês de junho e entre os meses de agosto a novembro (Fig. 1).

\subsection{Amostragem}

\subsubsection{Coleta das amostras de $\mathrm{CH}_{4}$ emitido pelo solo}

As amostras de ar emitido pelo solo (Tabela 1) foram coletadas para análise de sua concentração e determinação das taxas de emissões de $\mathrm{CH}_{4}$ na interface solo-atmosfera em intervalos de $30 \mathrm{~min}$ a partir da instalação da base (anel) da câmara estática e, em intervalos de 1 a 10 min, seringas foram conectadas a câmara de concentração para uso manual. As câmaras utilizadas foram de PVC (cloreto de polivinil) de formato frustum, com $12 \mathrm{~cm}$ de altura e 24 e $25 \mathrm{~cm}$ de diâmetro, a base do anel apresenta diâmetro de $25 \mathrm{~cm}$ e altura de $9 \mathrm{~cm}$. Para determinar o volume exato da

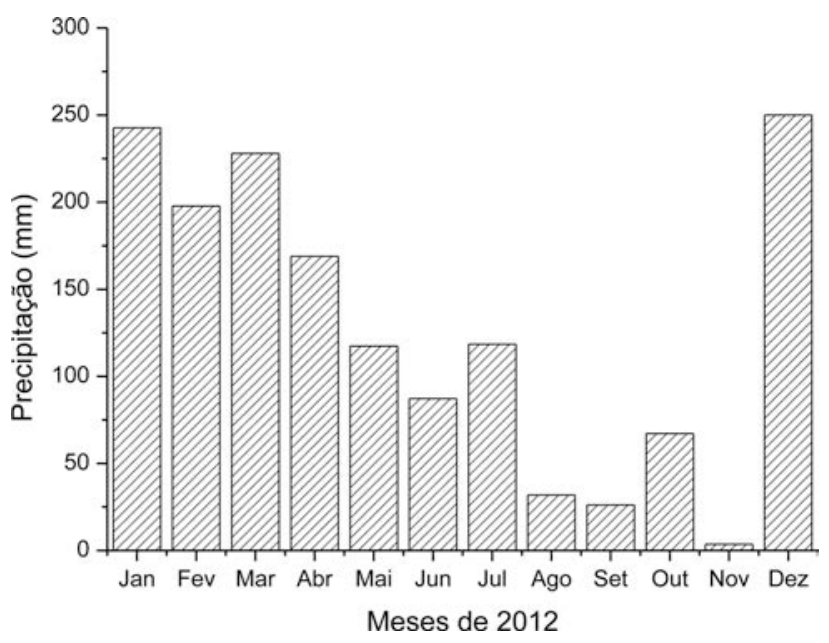

Figura 1 - Média mensal de precipitação no município de Belterra - PA. Fonte: Instituto Nacional de Meteorologia. Disponível em: www.inmet. gov.br/sim/sonobra/convenionais.php. 
Tabela 1 - Período de coleta e número (n) de amostragem analisadas em cada estação durante o ano de 2012 quanto à concentração e fluxo de metano $\left[\mathrm{CH}_{4}\right]$, na Floresta Nacional do Tapajós (FNT).

\begin{tabular}{|c|c|c|c|c|c|}
\hline \multirow[t]{2}{*}{ Local } & \multirow[t]{2}{*}{ Estação } & \multicolumn{2}{|c|}{ Período de coleta } & \multicolumn{2}{|c|}{$\mathrm{N}\left[\mathrm{CH}_{4}\right]$} \\
\hline & & Solo & Perfil vertical da floresta & Solo & Perfil \\
\hline & Chuvosa & Dez/12 (06) & Fev/12 $(01,03,10,13)$ & 12 & 38 \\
\hline \multirow[t]{6}{*}{ FNT } & & & Dez/12 (13) & & \\
\hline & Intermediária & Jun/12 (29) & & 23 & \\
\hline & & $\mathrm{Jul} / 12(13)$ & & & \\
\hline & Seca & Out/12 (19) & $\mathrm{Ago} / 12(03,20)$ & 24 & 37 \\
\hline & & Nov/12 (30) & Out/12 $(05,11)$ & & \\
\hline & & & Nov/12 (30) & & \\
\hline
\end{tabular}

câmara estática, todas as bases têm a sua altura medida até o solo em três pontos diferentes. Paralelamente foi determinada a temperatura do ar e do solo em ${ }^{\circ} \mathrm{C}$ através de Termopares (Cooper - Constantan).

O procedimento para obtenção da amostra, deu-se da seguinte maneira: ajustou-se a câmara de PVC sobre o anel para proporcionar a vedação da câmara estática para acumular o ar em seu interior. Posteriormente, coletou-se a primeira amostra de gás (tempo $1 \mathrm{~min}$ ), para isso, foi utilizada uma seringa de polipropileno de $20 \mathrm{~mL}$ equipada com uma válvula de fechamento no orifício de saída. Esse mesmo procedimento foi repetido durante os três tempos restantes (10, 20 e $30 \mathrm{~min})$. As câmaras estáticas foram instaladas em quatro pontos ao redor da torre, onde em cada ponto foram instaladas três câmaras para a determinação das medidas de fluxos de gases do solo para atmosfera, totalizando 12 câmaras em uma área aproximada de 0,5 hectares. $\mathrm{O}$ material coletado foi transportado para o Laboratório da EMBRAPA-Santarém onde foram analisadas num intervalo de 48 horas após a coleta usando a técnica de cromatografia gasosa.

\subsubsection{Coleta das amostras de $\mathrm{CH}_{4}$ no perfil vertical da floresta}

As amostras de ar atmosférico foram coletadas durante as estações chuvosa e seca (Tabela 1). A amostragem foi feita ao longo do perfil da torre, sendo que os níveis de altura corresponderam a $(2 \mathrm{~m})$ próximo ao solo, no subbosque $(16 \mathrm{~m})$ e próximo ao topo do dossel $(36 \mathrm{~m})$ e acima das copas $(63 \mathrm{~m})$ de altura. As coletas foram realizadas nos horários de 11 às 15 horas local, devido à atmosfera apresentar maior camada limite diurna, isso implica no maior escoamento de gases do ecossistema para atmosfera. Essas amostras serviram para análise da concentração e fluxo de metano no perfil vertical da floresta.

As amostras de ar foram puxadas por uma bomba através do tubo de teflon com $6 \mathrm{~mm}$ de diâmetro que esteve fixado a torre, sendo que, na extremidade do tubo continha um filtro de ar (PALL 0,45 $\mu \mathrm{m}$ PTFE ACRODISC CR) para evitar a contaminação de impurezas e posteriormente o teflon foi conectado aos frascos de vidros com capacidade de $1 \mathrm{~L}$ para armazenar a amostra de ar atmosférico, mas antes disso a umidade do ar era removida quimicamente com DRIERITE ${ }^{\mathrm{TM}}$ antes da amostra ser armazenada.

Antes de cada amostragem o ar acumulado no tubo era expelido durante 5 minutos para garantir que o ar coletado estivesse na altura desejada do perfil da floresta. As análises por cromatografia gasosa dessas amostras foram realizadas no Laboratório de Química Atmosférica (LQA) do IPEN (Instituto de Pesquisas Energéticas e Nucleares), São Paulo.

\subsubsection{Temperatura e umidade do solo}

A temperatura em graus Celsius $\left({ }^{\circ} \mathrm{C}\right)$ do ar foi medida através do uso do Termo higrômetro Digital Portátil ITHT 2220 e a temperatura do solo pelo Termômetro Digital do tipo Espeto da marca Taylor que foi introduzido no solo a uma profundidade de $5 \mathrm{~cm}$, próximo a câmera. A umidade do solo foi mensurada em percentagem através do Sistema Portátil HYDROSENSE ${ }^{\mathrm{TM}}$ Modelo CS620, CD620 a $12 \mathrm{~cm}$ de profundidade em três pontos distintos ao entorno da câmara estática de concentração para obter a média da umidade do solo in situ.

\subsection{Análise das amostras de $\mathrm{CH}_{4}$ - Cromatografia gasosa}

As amostras de ar do solo analisadas no Laboratório da EMBRAPA-Santarém mediram as concentrações de $\mathrm{CH}_{4}$ por cromatografia gasosa, através do cromatógrafo SHIMADZU (14A), com detector de chama (FID). As temperaturas do injetor, do detector e da coluna foram ajustadas para $125^{\circ} \mathrm{C}, 125^{\circ} \mathrm{C}$ e $40{ }^{\circ} \mathrm{C}$, respectivamente. $\mathrm{O}$ gás carreador foi o $\mathrm{N}_{2}$ com fluxo de $30 \mathrm{~mL} \cdot \mathrm{min}^{-1}$. Os picos desses gases foram comparados através de padrões primários $\left(\mathrm{P}_{\text {alto }}=1,810 \mathrm{ppm} \mathrm{CH}_{4} ; \mathrm{P}_{\text {baixo }}=0,910 \mathrm{ppm} \mathrm{CH}_{4}\right)$. As áreas dos picos foram integradas utilizando-se software da HEWLETT PACKARD (HPCHEM).

As amostras de ar do perfil vertical da floresta foram analisadas no LQA do IPEN através de um sistema integrado de análise dos gases $\mathrm{CO}_{2}, \mathrm{CH}_{4}, \mathrm{CO}, \mathrm{N}_{2} \mathrm{O}, \mathrm{H}_{2}$ e $\mathrm{SF}_{6}$, denominado MAGICC (Multiple Analysis of Gases Influence Climate Change), desenvolvido pelo ESRL/NOAA 
(Earth System Research Laboratory / National Oceanic Atmospheric Administration). A precisão da análise está de acordo com o padrão de referência internacional do NOAA ver descrição detalhada (D’ Amelio, 2006; Basso, 2011).

\subsection{Método quantitativo para determinar o fluxo de $\mathrm{CH}_{4}$}

\subsubsection{Determinação do fluxo de $\mathrm{CH}_{4}$ do solo}

A determinação do fluxo de metano emitido pela superfície do solo é feita a partir da variação temporal da sua concentração no interior da câmara. A concentração de metano em uma amostra de gás pode ser escrita como a razão entre sua pressão parcial $\left(p_{i}\right)$ e a pressão total $(p)$, ou pela razão entre o número de moles de $\mathrm{CH}_{4}\left(n_{\mathrm{CH}_{4}}\right)$ e o número total de moles da mistura $\left(n_{t}\right)$. O número de moles de uma substância presente na amostra é dado pela razão entre a massa da substância $\left(m_{C_{4}}\right)$ e sua massa molar $\left(M_{\mathrm{CH}_{4}}\right)$ ou $n_{\mathrm{CH}_{4}}=m_{\mathrm{CH}_{4}} / M_{\mathrm{CH}_{4}}$. Adotando-se uma variação no número de moles de metano $\left(\Delta n_{C H_{4}}\right)$, e aplicando-se a equação dos gases ideais $(p V=n R T / M)$, pode-se escrever:

$$
\frac{\Delta n_{\mathrm{CH}_{4}}}{n_{t}}=\frac{\Delta m_{\mathrm{CH}_{4}} R T}{M_{\mathrm{CH}_{4}} P V}=\Delta x_{\mathrm{CH}_{4}}
$$

ou

$$
\Delta m_{\mathrm{CH}_{4}}=\frac{\Delta x_{\mathrm{CH}_{4}} p V M_{\mathrm{CH}_{4}}}{R T}
$$

onde $p$ é a pressão total (atm), $V$ o volume total (litros), $M_{\mathrm{CH}_{4}}$ é a massa molar do metano $\left(16,04 \mathrm{gmol}^{-1}\right), R$ é a constante dos gases $\left(0,082 \mathrm{~atm} \mathrm{~L} \mathrm{~mol}^{-1} \mathrm{k}^{-1}\right)$ e $T$ é a temperatura $(K)$. Admitindo-se que a variação do fluxo através da área $A\left(\mathrm{~m}^{2}\right)$ é constante durante um intervalo de tempo $\Delta t$, pode-se escrever o fluxo $\Phi_{\mathrm{CH}_{4}}\left(\mathrm{em} \mathrm{mg} \mathrm{CH} \mathrm{Cm}^{-2} \mathrm{dia}^{-1}\right)$ como:

$\Phi_{C_{4}}=\frac{\Delta \chi_{C H_{4}} p V M_{C_{4}}}{\Delta t A R T}=\frac{p V M_{C H_{4}}}{A R T} \frac{\Delta \chi_{C H_{4}}}{\Delta t}=\frac{p V M_{C H_{4}}}{A R T} \frac{\partial \chi_{C H_{4}}}{\partial t}$

A mais importante variável na Eq. (3) é ${ }^{\partial} \chi_{\mathrm{CH}^{4}} /{ }_{\partial} t$, que é derivada das medidas de concentração. Todas as demais variáveis são medidas diretamente no momento da coleta. A grandeza ${ }^{\partial} \chi_{\mathrm{CH}^{4} /{ }_{\partial} t}$ é estimada a partir da regressão linear, considerando-se ${ }^{\partial} \chi_{\mathrm{CH}^{4}} /{ }_{\partial} t$ como o "b" em $X=X_{0}+b t$, e o coeficiente de correlação r entre $X$ e $t$ é uma medida da incerteza em ${ }^{\partial} \chi_{\mathrm{CH}^{4}} /{ }_{\partial} t$. Para se utilizar a regressão linear na obtenção de ${ }^{d} \chi_{\mathrm{CH}^{4}} /{ }_{\partial} t$, considera-se o fluxo constante durante o tempo de coleta das amostras (Marani, 2007).
2.5.2. Determinação do fluxo de $\mathrm{CH}_{4}$ no perfil vertical da floresta

Para calcular a razão de mistura de cada gás na camada do dossel foi realizada a interpolação dos dados entre os níveis de acordo com a Eq. (4).

$$
\frac{d C}{d t}=P-k\left(C-C_{t}\right)
$$

Onde $C$ é a razão de mistura do gás na camada do dossel, $P$ e a produção líquida da camada incluindo o fluxo soloatmosfera, $K$ e um coeficiente da troca entre a camada do dossel e da atmosfera acima e $C_{t}$ é a razão de mistura do gás na atmosfera acima da copa das árvores. Faz-se o mesmo procedimento da Eq.(4) para o $\mathrm{CO}_{2}$ para obter a seguinte relação:

$$
\frac{d\left[\mathrm{CH}_{4}\right]}{d\left[\mathrm{CO}_{2}\right]}=\frac{P_{\mathrm{CH}_{4}} k\left(\left[\mathrm{CH}_{4}\right]-\left[\mathrm{CH}_{4}\right]_{t}\right)}{P_{\mathrm{CO}_{2}} k\left(\left[\mathrm{CO}_{2}\right]-\left[\mathrm{CO}_{2}\right]_{t}\right)}
$$

Quando a troca $\left(K\left(C-C_{t}\right)\right)$ é relativamente pequena para a emissão de gases traço então se tem:

$$
\frac{d\left[\mathrm{CH}_{4}\right]}{d\left[\mathrm{CO}_{2}\right]} \approx \frac{P_{\mathrm{CH}_{4}}}{P_{\mathrm{CO}_{2}}}
$$

Assumindo que os processos de transporte para todos os gases traços são similares entre a camada de dossel da floresta e da atmosfera acima. A quantidade $d\left[\mathrm{CH}_{4}\right] / d$ $\left[\mathrm{CO}_{2}\right]$ em cada estação foi calculada pela regressão linear ortogonal.

O fluxo de $\mathrm{CO}_{2}\left(J_{\mathrm{CO}_{2} \text { solo }}\right)$ do solo foi medido através da câmara estática de concentração conectada a um analisador de gás por infravermelho - IRGA (Li-8000). A emissão de $\mathrm{CO}_{2}$ do ecossistema foi estimada pela razão $(\rho=2,4)$ do fluxo do solo baseado nos estudos de respiração do solo (Chambers et al. 2004). A estimativa do fluxo de $\mathrm{CH}_{4}$ foi calculada pela Eq. (7) em $\mathrm{mg} \mathrm{CH} \mathrm{CH}_{4} \mathrm{~m}^{-2} \mathrm{dia}^{-1}$ (Carmo et al. 2006).

$$
P_{\mathrm{CH}_{4}} \approx \rho J_{\mathrm{CO}_{2} \text { solo }} \frac{d\left[\mathrm{CH}_{4}\right]}{d\left[\mathrm{CO}_{2}\right]}
$$

\subsection{Análise dos dados}

Os dados foram submetidos ao tratamento estatístico de normalidade a partir do teste de Kolmogorov-Smirnov, admitindo-se $p<0,05$ como nível de significância. $\mathrm{O}$ teste utilizado demostrou que os dados apresentavam distribuição normal. Os resultados foram expressos através da média \pm desvio padrão (DP). A dependência da concentração e fluxo de $\mathrm{CH}_{4}$ em relação à temperatura e umidade do solo foi avaliada a partir da significância dos coeficientes de correlação de Pearson e a estimativa do fluxo de $\mathrm{CH}_{4}$ no perfil vertical da floresta foi avaliada através da regressão linear com significância estatística de $p<0,05$. O efeito da sazonalidade na concentração de $\mathrm{CH}_{4}$ no perfil vertical da floresta durante as estações úmida e seca foi investigado através do teste $t$. O software 
Origin 8.5.1 foi utilizado na elaboração de gráficos e testes estatísticos.

\section{Resultados e Discussão}

\subsection{Concentração e fluxo de $\mathrm{CH}_{4}$ do solo}

A concentração de metano na interface solo-atmosfera na região da FNT no km 67 oscilou de 1,227 a 5,274 ppm e apresentou (média \pm desvio padrão) de 2,291 $\pm 0,340 \mathrm{ppm}$ durante o período de investigação (11 às 15horas-local), sendo que, a menor produção desse gás foi no mês de junho em torno de 1,818 $\pm 0,507$ ppm mês que corresponde a transição entre o período chuvoso para o seco e a maior concentração em dezembro (início do período chuvoso para o ano de 2013) com valor igual a 2,773 $\pm 0,847$ ppm (Fig. 2a). O fluxo de metano do solo variou de $-0,50 \pm 1,36 \mathrm{mg}$ de $\mathrm{CH}_{4} \mathrm{~m}^{-2} \mathrm{dia}^{-1}$ em novembro (período seco) a $1,45 \pm 2,75 \mathrm{mg}$ de $\mathrm{CH}_{4} \mathrm{~m}^{-2} \mathrm{dia}^{-1}$ em dezembro para o ano de 2012 (Fig. 2b). A taxa média da emissão de metano do solo para atmosfera foi de $0,45 \pm 0,71 \mathrm{mg}$ de $\mathrm{CH}_{4} \mathrm{~m}^{-2} \mathrm{~d}^{-1}$ o que corresponde para um período de um ano, aproximadamente $1,64 \mathrm{Mg}$ de $\mathrm{CH}_{4} \mathrm{ha}^{-1}$. Se extrapolarmos para toda a FLONA Tapajós, obtém-se um valor igual a $0,89 \mathrm{Gg}$ de $\mathrm{CH}_{4} \mathrm{a}^{-1}$.

A umidade do solo na Amazônia é diretamente afetada pelo regime sazonal de precipitação (Fig. 1). Neste trabalho, a umidade média do solo a $12 \mathrm{~cm}$ de profundidade foi de $20,9 \%$ variando de 11,1 a $34,7 \%$ nos meses de novembro e junho, respectivamente. A temperatura média do solo a $5 \mathrm{~cm}$ de espessura foi de $25,5{ }^{\circ} \mathrm{C}$ sendo a mínima em junho $24,4{ }^{\circ} \mathrm{C}$ e a máxima em dezembro $27,0{ }^{\circ} \mathrm{C}$. A variação da umidade e temperatura do solo foi significativa $(p<0,05)$.

Para analisar a variação da concentração e fluxo de $\mathrm{CH}_{4}$ do solo para atmosfera foi feita a correlação de Pearson $(r)$ com a temperatura do solo para verificar a associa-

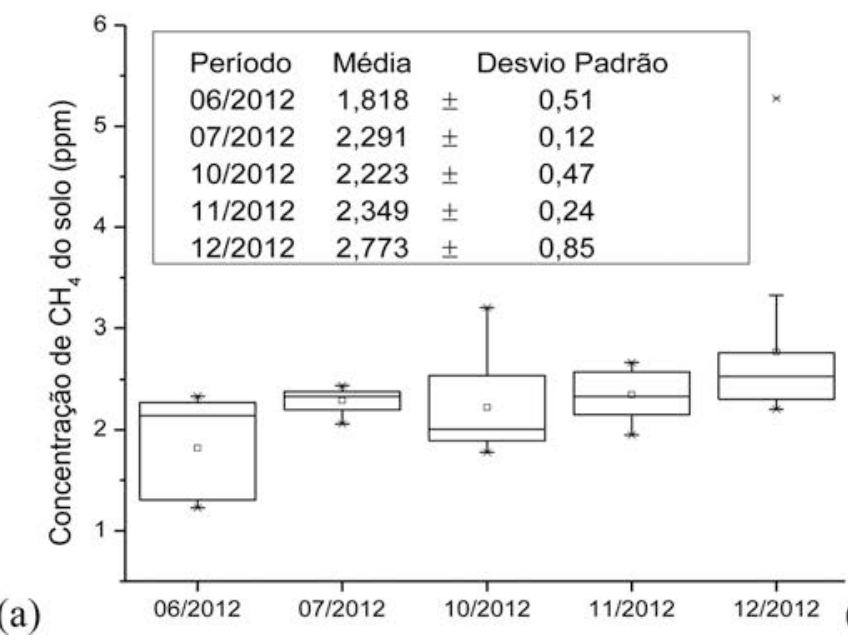

ção entre essas variáveis. Posteriormente, aplicou-se a técnica de regressão linear para determinar $\left(R^{2}\right)$ atuando diretamente na flutuação de $\mathrm{CH}_{4}$ nos meses de investigação. Observou-se, então, uma relação estatisticamente significativa para a produção e emissão de $\mathrm{CH}_{4}\left(\mathrm{r}=0,96\right.$ e $\mathrm{R}^{2}$ $=0,92)$ e $\left(r=0,59\right.$ e $\left.R^{2}=0,34\right)$, respectivamente (Fig. 3$)$.

Já em analogia ao teor de umidade no solo a associação foi significativa para a produção de metano, porém decrescente $r=-0,63$, o coeficiente de determinação foi de $\mathrm{R}^{2}=0,39$. A taxa de variação do gás não apresentou índice estatístico significativo (Fig. 4b).

De acordo com a Fig. 3a observou-se que a variação da temperatura no solo pode aumentar à atividade microbiana, aumentando desta forma a produção de metano (Escobar, 2008). Só que, parte dessa produção pode ser consumida por bactérias metanotróficas as quais obtêm energia e carbono da oxidação do $\mathrm{CH}_{4}$, uma vez que, a influência da temperatura no solo explica $34 \%$ do efluxo desse gás para atmosfera (Fig. 3b).

A umidade no solo favorece o desenvolvimento de bactérias metanogênicas, que por sua vez produzem metano a partir da decomposição da matéria orgânica disponível no solo e na serrapilheira. Entretanto, o que se observa é uma relação negativa, ou seja, com o aumento da umidade no solo diminuiu a concentração de metano, porém, pode existir uma faixa ótima de saturação nesse solo variando entre 10 e $25 \%$ (Fig. $4 \mathrm{a}$ ) o qual pode beneficiar uma melhor atividade dos microrganismos anaeróbicos.

Apesar da associação entre as variáveis ambientais (temperatura e umidade do solo) não serem altamente significativa à Fig. 5 apresenta o comportamento do fluxo de $\mathrm{CH}_{4}$ no solo de acordo com o comportamento dessas variáveis ao longo do período amostral.

A produção média de metano no solo 2,291 \pm 0,340 ppm $(2291 \pm 340 \mathrm{ppb})$ esteve acima da média global para este gás na atmosfera, o qual corresponde a (a)

Figura 2 - Concentração (a) e fluxo (b) de $\mathrm{CH}_{4}$ do solo para os meses de 2012.

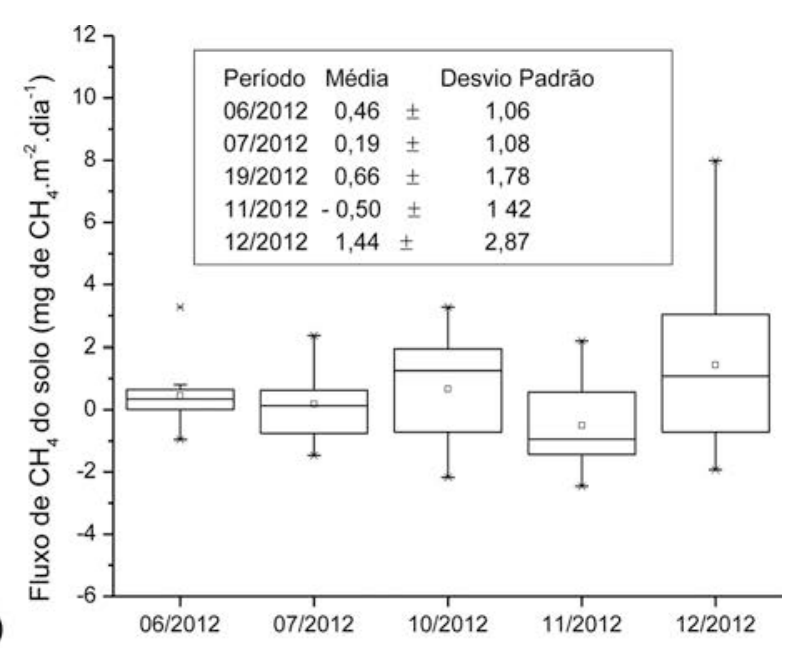



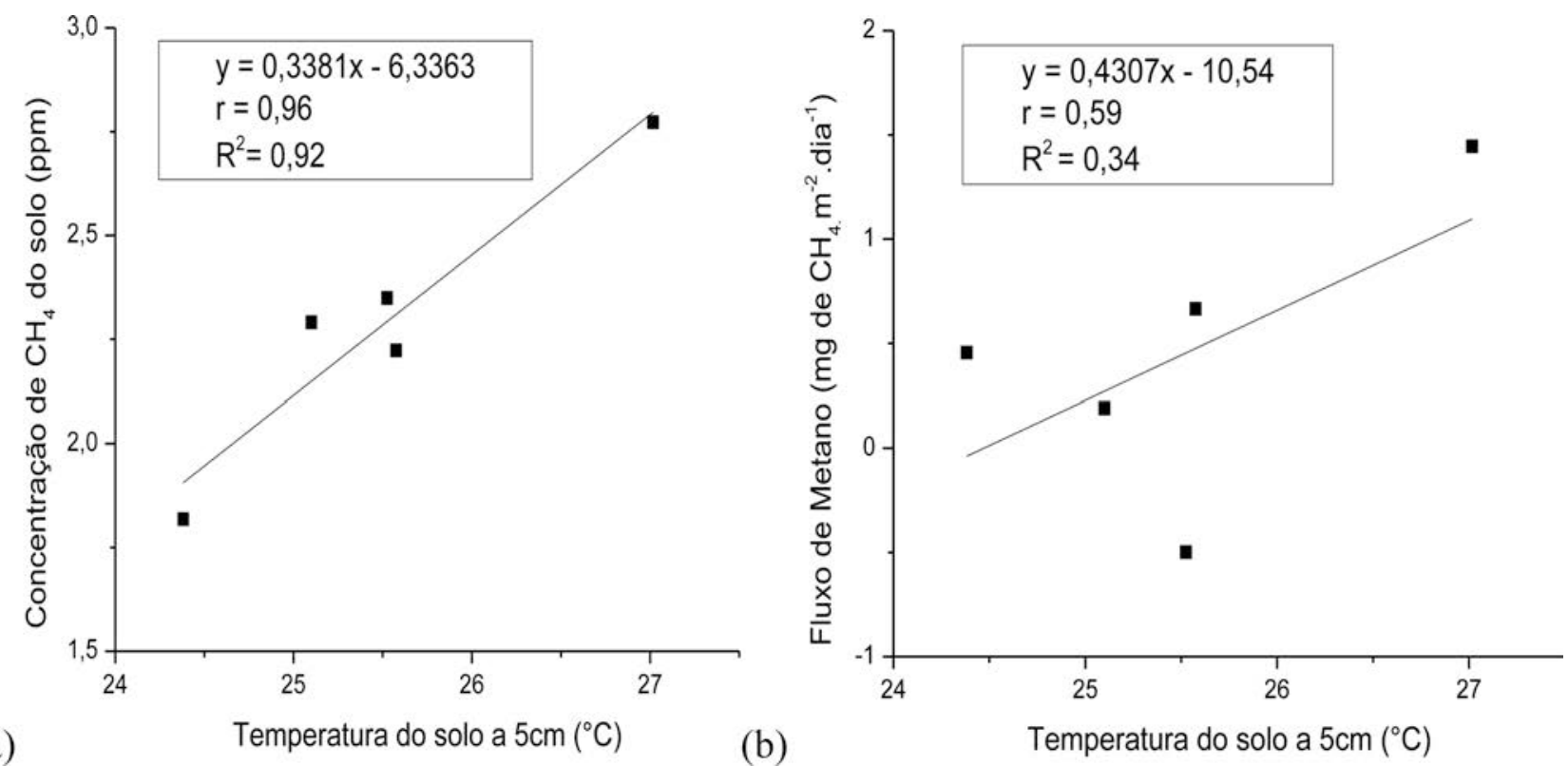

Figura 3 - Correlação e regressão da concentração (a) e fluxo de metano (b) do solo com a temperatura do solo a $5 \mathrm{~cm}$ de profundidade.
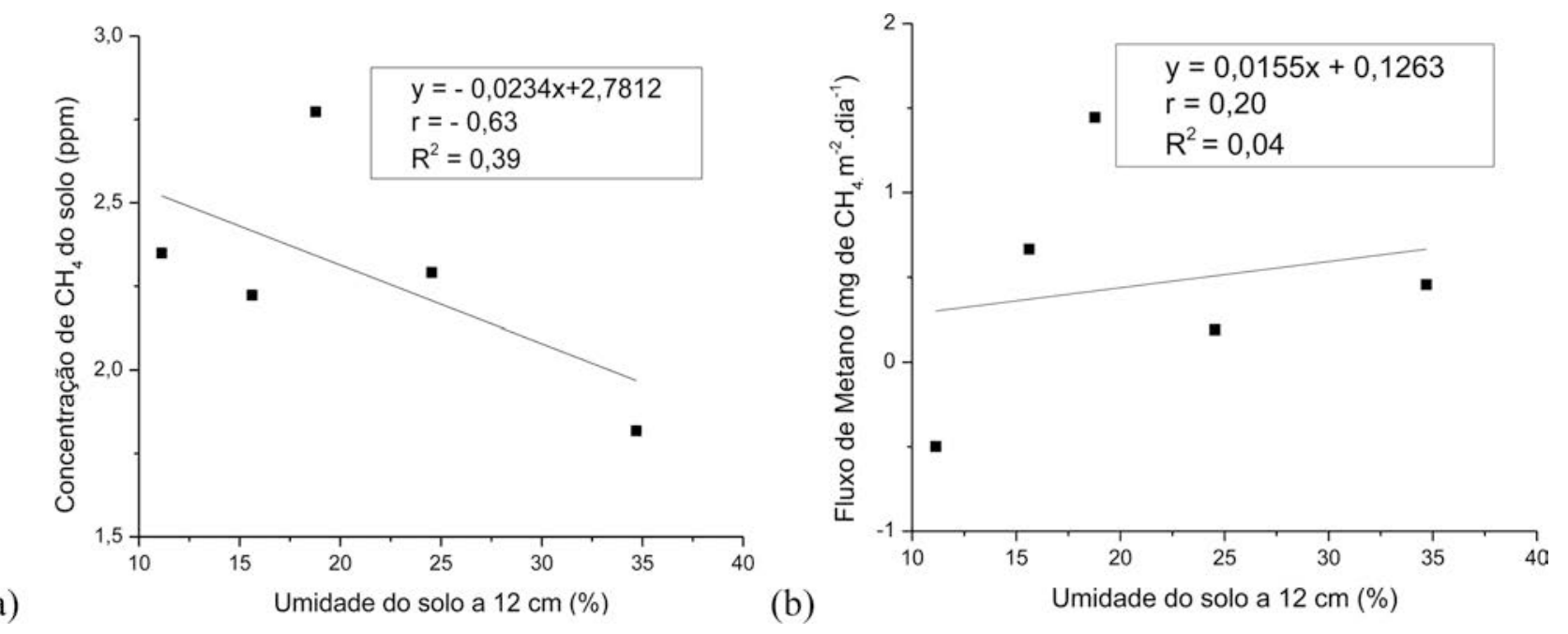

Figura 4 - Correlação e regressão da concentração (a) e fluxo de metano (b) do solo com a umidade do solo a 12 cm de profundidade.

$1,800 \mathrm{ppm}$ (Keppler et al. 2006) e $1813 \pm 2$ ppb para o ano de 2011 (WMO, 2012). Oliveira Junior (2006) apresentou valores de 39 e $59 \%$ superiores à concentração de 2 ppm, no período seco e úmido, respectivamente a uma profundidade de $5 \mathrm{~cm}$ para a mesma área de estudo.

A variação do fluxo de $\mathrm{CH}_{4}$ foi de $-0,34$ a $7,99 \mathrm{mg}$ de $\mathrm{CH}_{4} \mathrm{~m}^{-2} \mathrm{~d}^{-1} \mathrm{e}$ a média para a emissão desse fluido na interface solo-atmosfera foi de $0,45 \pm 0,71 \mathrm{mg}$ de $\mathrm{CH}_{4} \mathrm{~m}^{-2} \mathrm{~d}^{-1}$. A maior parte das medidas apresentaram resultados de fluxo positivo, indicando uma emissão de metano para atmosfera, no entanto, pesquisas realizadas por Keller et al. (2005) e Moura (2010) encontraram fluxos negativos. $\mathrm{O}$ primeiro quantificou uma variação entre $-0,3 \pm 0,2 \mathrm{e}$ $-0,1 \pm 0,9 \mathrm{mg} \mathrm{CH} \mathrm{Cm}^{-2} \mathrm{dia}^{-1}$ em solo do tipo LATOS-
SOLO VERMELHO e em ARGISSOLO alterando entre $1,0 \pm 0,2 \mathrm{e}-0,9 \pm 0,3 \mathrm{mg} \mathrm{CH}_{4} \mathrm{~m}^{-2} \mathrm{dia}^{-1}$ em solos não perturbados pelo corte seletivo de madeira na FNT no $\mathrm{km} 83$. E o segundo, uma média de $-1,17 \pm 0,28 \mathrm{mg} \mathrm{de} \mathrm{CH}_{4} \mathrm{~m}^{-2} \mathrm{~s}^{-1}$ na FNT no km 67. Nestes períodos o solo atuou como um sumidouro de metano.

Apesar do saldo positivo, neste trabalho, grande parte das coletas apresentaram valores negativos para o fluxo durante as medidas, principalmente no período de estiagem (novembro) em que se obteve uma absorção de metano pelo solo de $-0,50 \pm 1,36 \mathrm{mg}$ de $\mathrm{CH}_{4} \mathrm{~m}^{-2} \mathrm{~d}^{-1}$ (Fig. 2b). Entretanto, Oliveira Junior (2006) obteve um comportamento positivo tanto para o período úmido quanto para o seco igual a $0,1696 \mathrm{mg} \mathrm{CH}_{4} \mathrm{~m}^{-2} \mathrm{~h}^{-1} \mathrm{e}$ 

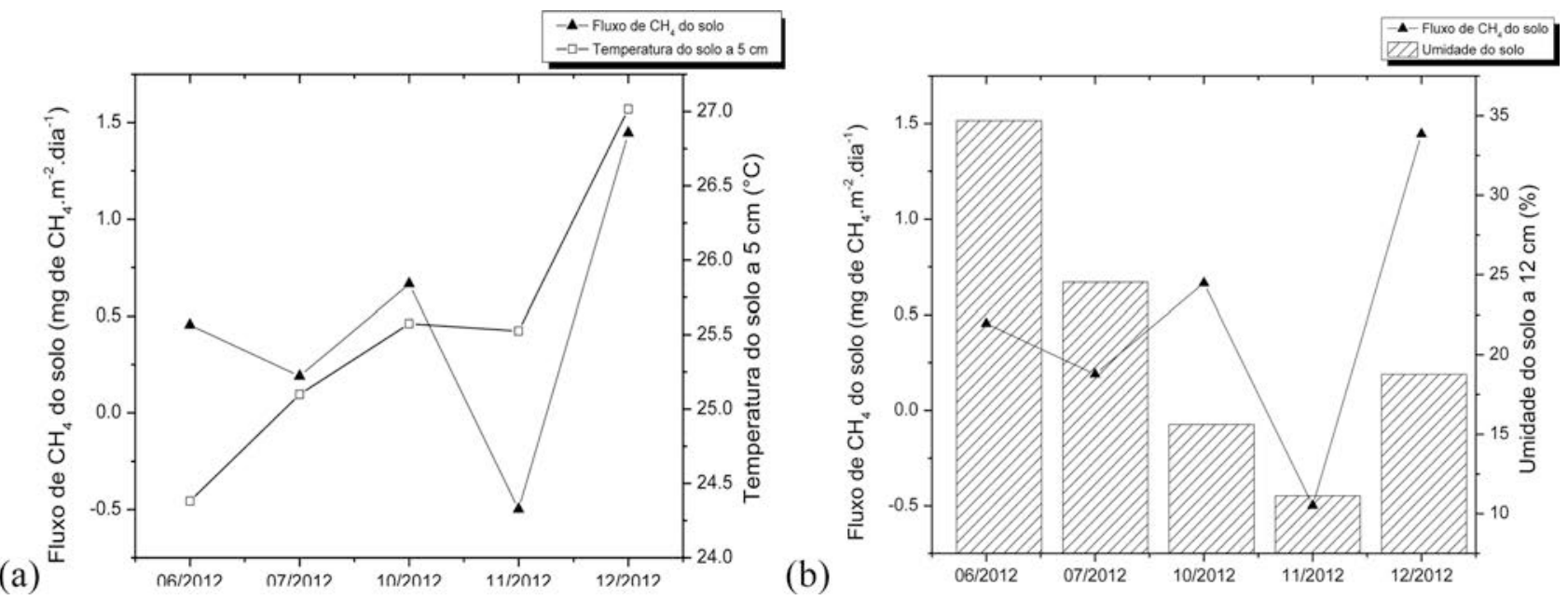

Figura 5 - Fluxo de metano do solo com as variáveis ambientais temperatura do solo (a) e umidade do solo (b) para os meses de 2012.

$0,1507 \mathrm{mg} \mathrm{CH}_{4} \mathrm{~m}^{-2} \mathrm{~h}^{-1}$, respectivamente, e um fluxo anual aproximado de $0,16 \mathrm{mg} \mathrm{CH}_{4} \mathrm{~m}^{-2} \mathrm{~h}^{-1}\left(14,08 \mathrm{~kg} \mathrm{ha}^{-1} \mathrm{ano}^{-1}\right)$.

É evidente que o estudo de gases traço, principalmente o metano na interface solo-atmosfera é de extrema complexidade, pois é sabido que os solos tropicais são um sumidouro para metano, porém, neste trabalho, assim como no de Oliveira Junior (2006) na FLONA Tapajós e com características semelhantes em relação ao tipo de solo e cobertura vegetal, o solo emitiu gás metano para atmosfera, mesmo levando-se em consideração o seu consumo no período seco. Segundo Castro et al. (1994) os solos florestais consomem menos metano quando se torna mais úmido. Isto pode estar diretamente associada à atuação de organismos metanogênicos (metanogênese), os quais catalisam a quebra da matéria orgânica, resultando na produção de $\mathrm{CH}_{4} \mathrm{e} \mathrm{CO}$, pois na camada superficial se concentra uma boa quantidade de liteira a qual pode servir de alimento para estes microrganismos.

A variação de temperatura na superfície do solo em torno de $2,6^{\circ} \mathrm{C}$ pode causar um efeito na atividade microbiológica em relação ao fluxo desse gás. Embora, o coeficiente de determinação $\left(R^{2}\right)$ possa explicar apenas $34 \%$ dessa emissão (Fig. 3a). No entanto, em relação à importância na produção/concentração de metano o $R^{2}$ explica $92 \%$ ainda que parte dessa produção seja absorvida pelo próprio solo. Dessa forma, é evidente que os fatores ambientais como a temperatura e a umidade do solo são relevantes no controle das taxas de variação do fluxo de metano (Fig. 5).

\subsection{Concentração e fluxo de $\mathrm{CH}_{4}$ no perfil vertical da floresta}

Na FNT a concentração de $\mathrm{CH}_{4}$ variou entre 1,801 a $1,928 \mathrm{ppm}$, sendo o valor (médio \pm desvio padrão) para todas as amostras iguais a $1,866 \pm 0,038 \mathrm{ppm}$, ou seja, $1866 \pm 38 \mathrm{ppb}$. Na estação chuvosa a concentração foi de $1,882 \pm 0,030 \mathrm{ppm}$ e durante o período seco foi de 1,832 $\pm 0,028 \mathrm{ppm}$. Aplicando o teste $t$, observou-se um resul- tado significativo $(p<0,05)$, ou seja, a diferença na concentração de $\mathrm{CH}_{4}$ igual a $0,05 \mathrm{ppm}$ entre as médias amostrais é expressiva o que caracteriza um efeito na produção de metano de acordo com a sazonalidade (Fig. 6).

A concentração de $\mathrm{CH}_{4}$ ao longo do perfil da floresta entre os compartimentos amostrados próximos ao solo, no sub-bosque, na copa e na atmosfera logo acima da floresta durante as estações úmida e seca (Fig. 7) não apresentaram diferenças significativas entre as alturas (Tabela 2).

Durante as campanhas realizadas a proporção de mistura do $\mathrm{CH}_{4}$ aumentou em relação à proporção de mistura do $\mathrm{CO}_{2}$ (Fig. 8).

Os valores médios de $\mathrm{d}\left[\mathrm{CH}_{4}\right] / \mathrm{d}\left[\mathrm{CO}_{2}\right]$ durante as estações de amostragem variaram em até uma ordem de grandeza. A média para o fluxo de $\mathrm{CO}_{2}$ na interface soloatmosfera variou de 5,6 a 6,2 $\mu \mathrm{mol}$ de $\mathrm{CO}_{2} \mathrm{~m}^{-2} \mathrm{~s}^{-1}$ e a emissão estimada de $\mathrm{CH}_{4}$ para o ecossistema variou de 6,7 a 24,4 mg de $\mathrm{CH}_{4} \mathrm{~m}^{-2} \mathrm{~d}^{-1}$ para as estações seca e chuvosa, respectivamente (Tabela 3 ).

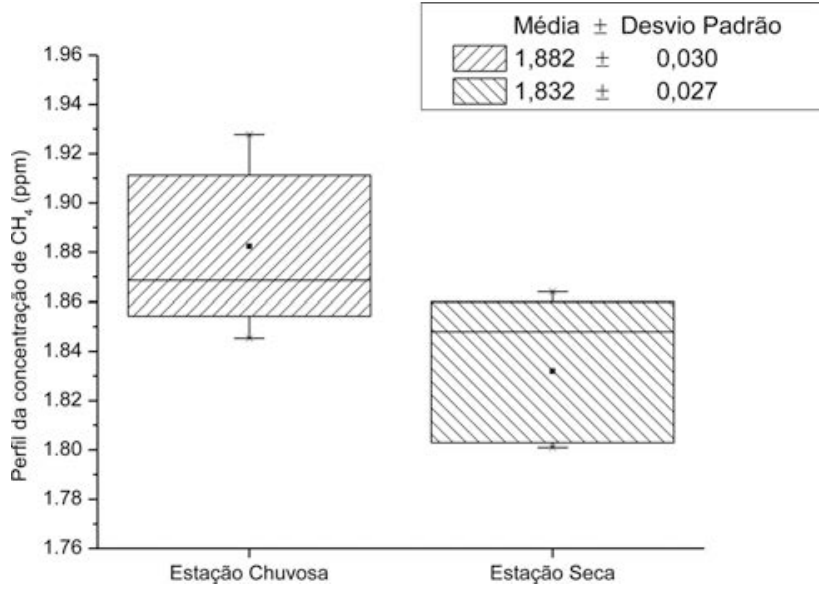

Figura 6 - Concentração de $\mathrm{CH}_{4}$ no perfil vertical da floresta durante as estações chuvosa e seca. 

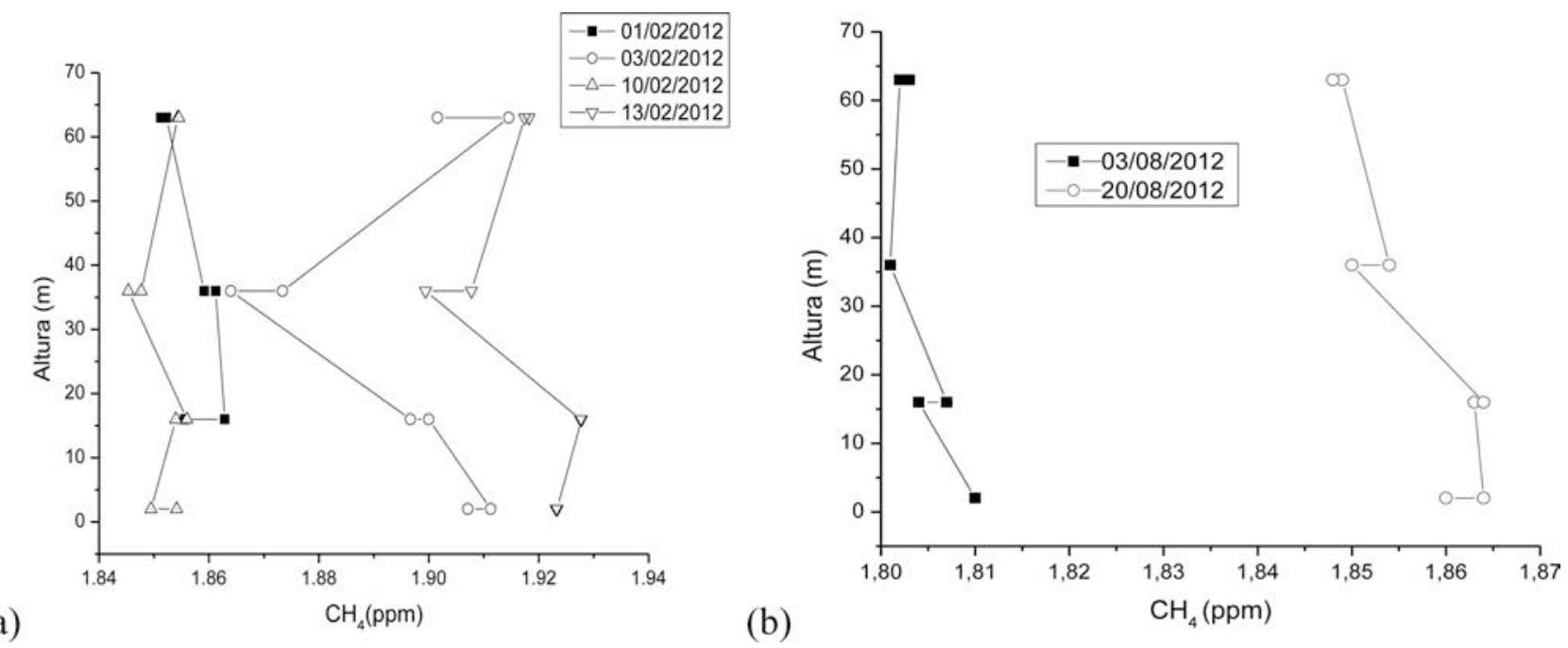

Figura 7 - Medidas de $\mathrm{CH}_{4}$ em diferentes alturas durante a estação chuvosa (a) e seca (b).

Tabela 2 - Média e valores de $p$ obtidos na análise não paramétrica de "Kruskal-Wallis" na comparação entre os valores das amostras de $\mathrm{CH}_{4}$ coletadas ao longo do perfil vertical da floresta entre as estações chuvosa e seca.

\begin{tabular}{|c|c|c|c|c|c|c|c|}
\hline Local & Item & Estação & Solo & Sub-Bosque & Copa & Acima das copas & $p$ \\
\hline & & & $(2 \mathrm{~m})$ & $(16 \mathrm{~m})$ & $(36 \mathrm{~m})$ & $(63 \mathrm{~m})$ & \\
\hline \multirow[t]{2}{*}{ FNT } & {$\left[\mathrm{CH}_{4}\right]$} & Chuvosa & 1,895 & 1,885 & 1,870 & 1,883 & 0,6138 \\
\hline & $(\mathrm{ppm})$ & Seca & 1,845 & 1,835 & 1,827 & 1,826 & 0,3024 \\
\hline
\end{tabular}

A taxa média da emissão de metano ao longo do perfil vertical da floresta para atmosfera foi de $15,5 \mathrm{mg}$ de $\mathrm{CH}_{4} \mathrm{~m}^{-2} \mathrm{~d}^{-1}$ o que corresponde para um período de um ano, aproximadamente $56,6 \mathrm{Mg}$ de $\mathrm{CH}_{4} \mathrm{ha}^{-1}$. Se extrapolarmos para toda a FLONA Tapajós obtém-se um valor corresponde a $29,8 \mathrm{Gg}$ de $\mathrm{CH}_{4} \mathrm{a}^{-1}$.

Os dados apresentados sobre a concentração de $\mathrm{CH}_{4}$ ao longo do perfil vertical da floresta neste trabalho foi de

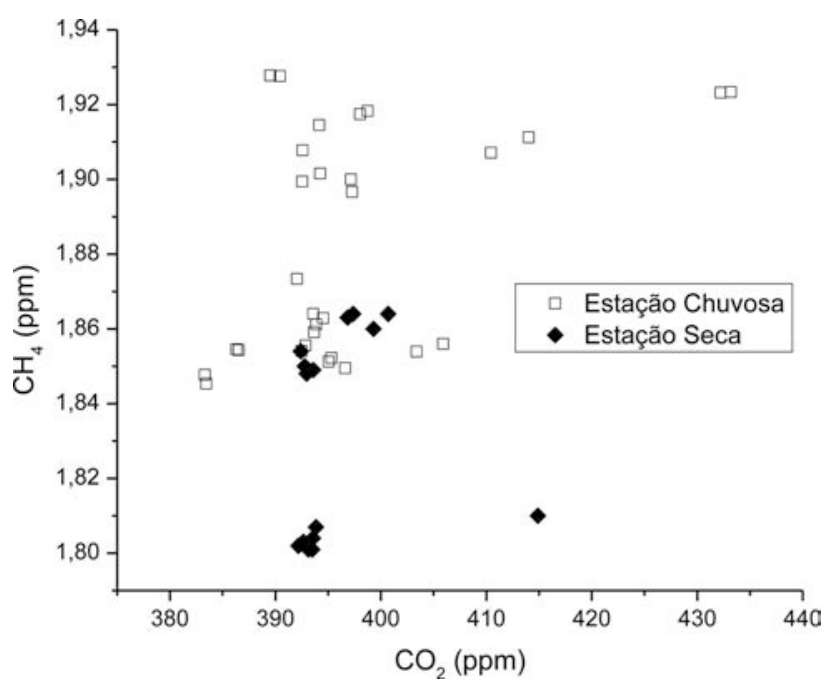

Figura 8 - Proporção de mistura de $\mathrm{CH}_{4}$ em relação ao $\mathrm{CO}_{2}$ para todos os perfis.
$1,866 \pm 0,038 \mathrm{ppm}(1866 \pm 38 \mathrm{ppb})$, levemente superior à média global para esse gás na atmosfera $1813 \pm 2 \mathrm{ppb}$ (WMO, 2012). Entretanto, foi abaixo dos resultados encontrados por Moura (2010) para a Floresta Nacional de Caxiuanã (2,080 ppm) e para Floresta Nacional do Tapajós $(2,110 \mathrm{ppm})$. Essa diferença na produção de $\mathrm{CH}_{4}$ nos perfis florestais pode estar associada ao nível de precipitação pluviométrica nos anos em que foram realizadas as pesquisas, sendo de, $2296 \mathrm{~mm} \cdot \mathrm{ano}^{-1}$ e $2200 \mathrm{~mm} \cdot \mathrm{ano}^{-1}$ para Caxiuanã e FLONA Tapajós, respectivamente. Enquanto que, para a FLONA Tapajós no ano de 2012 (ano de realização do presente trabalho) foi de 1539,2 $\mathrm{mm}$.

Foi possível observar uma diferença na produção de $\mathrm{CH}_{4}$ influenciada pela sazonalidade meteorológica entre o período chuvoso e de estiagem para o conjunto de dados amostrados. A maior geração de $\mathrm{CH}_{4}$ durante a estação úmida pode estar relacionada à presença de microsítios anaeróbicos em troncos de árvores, bromélias onde a água da chuva ou a umidade elevada podem criar um ambiente anóxico favorável à sua produção por meio de atividades de microrganismos anaeróbicos atuando na decomposição da matéria orgânica presente na floresta em diferentes alturas (Fig. 6).

Ao longo do perfil vertical da floresta foram encontrados valores diferentes para a concentração de metano (Fig. 7), embora essa diferença não seja expressiva do ponto de vista estatístico (Tabela 3) ainda existe a hipótese proposta por Keppler et. al. (2006) de que existe a produ- 
Tabela 3 - A taxa de $d\left[\mathrm{CH}_{4}\right] / d\left[\mathrm{CO}_{2}\right]$ calculado para dois períodos de amostragem na Floresta Nacional do Tapajós (FNT) e o fluxo de $\mathrm{CH}_{4}$ correspondente ao fluxo de $\mathrm{CO}_{2}$ do solo.

\begin{tabular}{|c|c|c|c|c|}
\hline Local & Estação & $d\left[\mathrm{CH}_{4}\right] / d\left[\mathrm{CO}_{2}\right]$ & Fluxo de $\mathrm{CO}_{2}$ do solo ( \pm desvio padrão) $\mu \mathrm{mol} \mathrm{m}{ }^{-2} \mathrm{~s}^{-1}$ & Fluxo de $\mathrm{CH}_{4}(\mathrm{mg}) \mathrm{CH}_{4} \mathrm{~m}^{-2} \mathrm{dia}^{-1}$ \\
\hline \multirow[t]{2}{*}{ FNT } & Chuvosa & $0,0012^{\mathrm{a}}$ & $6,2 \pm 1,7$ & 24,4 \\
\hline & Seca & 0,0004 & $5,6 \pm 3,1$ & 6,7 \\
\hline
\end{tabular}

${ }^{\mathrm{a}}$ Regressão estatisticamente significativa $(p<0,05)$.

ção de metano derivada de plantas vivas ou mortas em condições aeróbicas. Crill et al. (2007) mostraram que a concentração média de $\mathrm{CH}_{4}$ medida na mesma área de estudo variou em torno de 1,700 e 1,900 ppmv. Além disso, coletas realizadas em sobrevoos na FLONA Tapajós encontraram valores de concentrações de $\mathrm{CH}_{4} \operatorname{logo}$ acima da floresta maiores do que em elevadas altitudes indicando que a superfície da vegetação corrobora como uma possível fonte de metano (D' Amelio, 2006; Basso, 2011). Pesquisadores utilizando a técnica de sensoriamento remoto constataram uma produção de $\mathrm{CH}_{4}$ significativa oriunda de florestas tropicas de fontes até então desconhecidas (Frankenberg et al. 2005; Bergamaschi et al. 2007; Schneising et al. 2009).

A formação de $\mathrm{CH}_{4}$ oriunda da floresta de terra firme, encontrada neste trabalho, principalmente no período de estiagem, também pode estar relacionado a fenômenos físicos como radiação UV e temperatura, que interagindo com folhas frescas e secas e com os componentes estruturais da planta como: pectina, lignina e celulose através de um processo fotoquímico direto podem estar contribuindo para a produção e posteriormente emissão de $\mathrm{CH}_{4} \mathrm{em}$ área de vegetação elevada, como a FLONA Tapajós (Vigano et al. 2008; McLeod et al. 2008; Bruhn et al. 2009; Qaderi e Reid, 2009). Além do mais, durante o período seco é comum à existência de focos de incêndios, o que pode contribuir para a concentração de metano suspenso no ar (Moura, 2010). Embora, sua concentração tenha sido menor do que o período chuvoso, essa diminuição do gás na atmosfera pode estar vinculada a um aumento das taxas de difusão do $\mathrm{CH}_{4}$ para o solo (Dorr et al. 1993; Striegl, 1993).

A FLONA Tapajós no km 67 apresentou um fluxo médio anual de metano igual a $15,5 \mathrm{mg} \mathrm{CH}_{4} \mathrm{~m}^{-2} \mathrm{dia}^{-1}$, sendo que, na fase mais intensa de chuva o fluxo de emissão correspondeu a $24,4 \mathrm{mg} \mathrm{CH} \mathrm{m}^{-2} \mathrm{dia}^{-1}$ demostrando uma alta emissão natural em relação ao período seco o qual registrou uma emissão de $6,7 \mathrm{mg} \mathrm{CH} \mathrm{CH}_{4} \mathrm{~m}^{-2} \mathrm{dia}^{-1}$ (Tabela 3). A associação observada de $\mathrm{CH}_{4}$ com o $\mathrm{CO}_{2}$ (Fig. 8) pode sugerir a existência de uma fonte de $\mathrm{CH}_{4}$ na camada do dossel devida à razão de mistura proporcional a esses gases e que a taxa de emissão para o metano varia de acordo com a estação (Tabela 3 ).

Basso (2011), encontrou fluxo médio anual de $\mathrm{CH}_{4}$ de $42 \mathrm{mg} \mathrm{CH} \mathrm{CH}_{4} \mathrm{~m}^{-2} \mathrm{dia}^{-1}$ e Miller et al. (2007) uma taxa anual de $35 \mathrm{mg} \mathrm{CH}_{4} \mathrm{~m}^{-2}$ dia $^{-1}$ ambas realizadas em sobrevoos sobre a FLONA Tapajós. Note que, os valores supra- citados estão bem acima da média encontrada neste estudo, no entanto, todos os dados indicam que o ecossistema florestal de terra firme é um potencial emissor de metano para atmosfera.

Carmo et al. (2006) usando medidas diretas da concentração de $\mathrm{CH}_{4}$ e $\mathrm{CO}_{2}$ em perfis verticais de florestas de terra-firme da Amazônia e medidas de fluxo de $\mathrm{CO}_{2}$ do solo, estimaram a emissão líquida de $\mathrm{CH}_{4}$ alterando entre 2 e $21 \mathrm{mg} \mathrm{CH}_{4} \mathrm{~m}^{-2}$ dia $^{-1}$ durante as estações seca e chuvosa de Caxiuanã, Manaus e Sinop. O que também corrobora com o pressuposto de que a vegetação de terra firme de fato é um potencial emissor de metano para atmosfera.

\section{Conclusão}

Por tudo isso, é evidente que a floresta de terra firme localizada na FLONA Tapajós tem um papel importante na produção e fluxo de $\mathrm{CH}_{4}$ desse ecossistema para atmosfera. Constatou-se a variabilidade sazonal da concentração e emissão desse gás ao longo do período de estudo, possivelmente em função das diferenças no volume pluviométrico durante a estação chuvosa e seca e ao efeito das alterações nos teores de umidade e temperatura do solo os quais podem favorecer a produção de $\mathrm{CH}_{4}$ durante o período chuvoso ou o consumo deste no período de estiagem em razão da atividade de microrganismos no solo.

É importante lembrar que, outros parâmetros podem ser levados em consideração no que diz respeito às fontes localizadas de produção e emissão de $\mathrm{CH}_{4}$ ao longo da estratificação vegetal como: emissão aeróbica pelas folhas (apesar de não ter apresentado diferença significativa), microsítios de produção anaeróbicas nas cascas dos troncos e galhos, cupins, emissão via transpiração das plantas e queima de combustível orgânico.

\section{Referências}

COSTA, D.H.M.; SILVA, J.N.M.; CARVALHO, J.O.P. Crescimento de árvores em uma área de terra firme na floresta nacional do Tapajós após a colheita de madeira. Revista de Ciência Agrária, n. 50, p. 63-76, 2008.

BASSO, L.S. Estudo da Emissão de Metano da Bacia Amazônica utilizando Perfis Verticais com Avião. Dissertação de Mestrado, Instituto de Pesquisa Energéticas e Nucleares /Autarquia Associada à Universidade de São Paulo, São Paulo, p. 103, 2011.

BERGAMASCHI, P.; FRANKENBERG, C.; MEIRINK, J.F.; KROL, M.; ENTENER, F.; WAGNER, T.; PLATT, U.; KAPLAN, J.O.; KORNER, S.; HEIMANN, M.; DLUGO- 
KENCKY, E.J.; GOEDE, A. Satellite cartography of atmospheric methane from SCIAMACHY on board ENVISAT: 2. Evaluation based on inverse model simulations, Journal of Geophysical Research - Atmospheres, v. 112, p. D2D02304, 2007.

BRUHN, D.; MIKKELSEN, T.N.; OBRO, J.; WILLATS, W.G.T.; AMBUS, P. Effects of temperature, ultraviolet radiation and pectin methyl esterase on aerobic methane release from plant material, Plant Biology, v. 11, ed. s1, p. 43-48, 2009.

CARMO, J.B.; KELLER, M.; DIAS, J.B.; DE CAMARGO, PB.; CRILL, P.A. Source of methane from upland forests in the Brazilian Amazon. Geophysical Research Letters, v. 33, n. L04809 p. 1-4, 2006.

CASTRO, M.S.; JERRY M.M.; STEUDLER, P.A.; CHAPMAN, J.W. Soil moisture as a predictor of methane uptake by temperate forests soils. Canadian Journal of Forest Research, v. 24, n. 9, p. 1805-1810, 1994.

CHAMBERS, J.Q.E.S.; TRIBUZI, L.C; TOLEDO, B.F; CRISPIM, N.; HIGUCHI, J.; SANTOS, A.C.; ARAUJO, B.; KRUIJT; NOBRE, A.D.; TRUMBORE, S.E. Respiration from a tropical forest ecosystem: Partitioning of sources and low carbon use efficiency, Ecol. Appl, v. 14, n. 4, p. S72-S88, 2004.

COSTA, D.H.M.; SILVA, J.N.M.; CARVALHO, J.O.P. Crescimento de árvores em uma área de terra firme na floresta nacional do Tapajós após a colheita de madeira. Revista de Ciência Agrária, v. 50, n. 1, p. 63-76, 2008.

CRILL, P.; KELLER, M.; SILVA, H.; DIAS, J.D.; ALBUQUERQUE, S.; CZEPIEL, P.; OLIVEIRA, R.C. Trace gas fluxes through-canopy measurements in an upland forest of the Eastern Brazilian Amazon. In: LBA-ECO 11th Science team Meeting, Salvador, 26-28 de setembro, 2007.

D’Amelio, M.T.S. Estudo de gases de efeito estufa na Amazônia. Dissertação de Mestrado, Instituto de Pesquisa Energéticas e Nucleares/Autarquia Associada à Universidade de São Paulo, São Paulo, 178 p, 2006.

DICKINSON, R.E.; CICERONE, R.J. Future global warming from atmospheric trace gases. Nature, v. 319, p. 109-115, 1986.

DORR, H.; KATRUFF, L.; LEVIN, I. Soil texture parameterization of the methane uptake in aerated soil. Chemosphere, v. 26, n. 1-4, p. 697-713, 1993.

HOUGHTON, J. The climate convention and the latest scientific understanding of climate change. Conference: World Renewable Energy Congress, Reading (United Kingdom), v. 5, p. 1-4, 1994.

KELLER, M.; VARNER, R.; DIAS, J.D.; SILVA, H.; CRILL, P.; DE OLIVEIRA, R.C.J.; ASNER, G.P. Soil-atmosphere Exchange of Nitrous Oxide, Nitric Oxide, Methane, and Carbon Dioxide in logged and undisturbed forest in the Tapajós National Forest, Brazil. Earth Interactions, v. 9, n. 23, p. 1-28, 2005.

KEPPLER, F.; HAMILTON, J.T.G.; BRASS, M.; RÖCKMANN, T. Methane emissions from terrestrial plants under aerobic conditions. Nature, v. 439, p. 187-191, 2006.

KUCK, L.R.; SMITH, T.; BALSLEY, B.B.; HELMIG, D.; CONWAY, T.J.; TANS, P.P.; DAVIS, K.; JENSEN, M.L.; BOGNAR, J.A.; ARRIETA, R.V.; RODRIQUEZ, R.;
BIRKS, J.W. Measurements of landscape-scale fluxes of carbon dioxide in the Peruvian Amazon by vertical profiling through the atmospheric boundary layer. Journal of Geophysical Research-Atmospheres, v. 105, n. D17, p. 22137-22146, 2000.

MARTENS, C.S.; SHAY, T.J.; MENDLOVITZ, H.P.; MATROSS, D.M.; SALESKA, S.; WOFSY, S.C.; WOODWARD, S.; MENTON, M.C.; MOURA, J.M.S.; CRIL, P.; MORAES, O.L.L.; LIMA, R.L. Radon fluxes in tropical forest ecosystems of Brazilian Amazonia: night-time $\mathrm{CO}_{2}$ net ecosystem exchange derived from radon and eddy covariance methods. Global Change Biology, v. 10, ed. 5, p. 618-629, 2004.

MARINI, L. Estudo da emissão de metano no Pantanal SulMatogrossense. Tese de Doutorado, Instituto de Pesquisas Espaciais, São José dos Campos, São Paulo, p. 110, 2007.

MCLEOD, A.R.; FRY, S.C.; LOAKE, G.J.; MESSENGER, D.J.; REAY, D.S.; SMITH, K.A.; YUN, B.W. Ultraviolet radiation drives methane emissions from terrestrial plant pectins. New Phytologist, v. 180, Ed.1, p. 124-132, 2008.

MILLER, J.B.; GATTI, L.V.; D’AMELIO, M.T.S.; CROTWELL, A.M.; DLUGOKENCKY, E. J.; BAKWIN, P.; ARTAXO, P.; TANS, P.P. Airborne measurements indicate large methane emissions from the eastern Amazon basin. Geophysical Research Letters, v. 34, n. L10809, p. 1-5, 2007.

MOURA, J.M.S. Fontes de metano em florestas tropicais da Amazônia: Análise da composição isotópica e uso de técnicas indiretas para determinação de balanços gasosos nesses ecossistemas. Tese de Doutorado. Universidade de São Paulo, Piracicaba, São Paulo, p. 108, 2010.

NEPSTAD, D.C.; MOUTINHO, P.; DIAS. M.B.; DAVIDSON, E.; CARDIONOT, G.; MARKEWITZ, D.; FIGUEIREDO, R.; VIANNA, N.; CHAMBERS, J.; RAY, D.; GUERREIROS, J.B.; LEFEBVRE, P.; STERNBERG, L.; MOREIRA, M.; BARROS, L.; ISHIDA, F.Y.; TOHLVER, I.; BELK, E.; KALIF, K.; SCHWALBE, K. The effects of partial through fall exclusion on canopy processes, aboveground production, and biogeochemistry of an Amazon forest. Jornal of Geophysical Research-Atmospheres, v. 107, n. D20, p. 53(1-18), 2002.

OLIVEIRA, R.C.J. Quantificação e caracterização química da água da chuva e de throughfall e fluxos de gases traço em Floresta de Terra Firme na Flona Tapajós, Belterra - Pará. Tese de Doutorado, Programa de Pós-Graduação em Geologia e Geoquímica/Universidade Federal do Pará, Belém, Pará, p. 143, 2006.

PAROTTA, J.A.; FRANCIS, J.K., DE ALMEIDA, R.R. Trees of the Tapajos: a photographic field guide. Rio Piedras: General Technical Report IITF-1, n. 1, p. 370, ed. 52, 1995.

PEREIRA, A.R.; ANGELOCCI, LR.; SENTELHAS, P.C. Agrometeorologia - Fundamentos e Aplicações Práticas. Guaíba: Editora Agropecuária, p. 478, 2002.

QADERI, M.M. E REID, D.M. Methane emissions from six crop species exposed to three components of global change: Temperature, ultraviolet-B radiation and water stress. Physiologia Plantarum, v. 137, ed. 2, p. 139-147, 2009.

SCHNEISING, O.; BUCHWITZ, M.; BURROWS, J.P.; BOVENSMANN, H.; BERGAMASCHI, P.; PETERS, W. 
Three years of greenhouse gas column-averaged dry air mole fractions retrieved from satellite - Part 2: Methane. Atmospheric Chemistry and Physics, v. 9, ed. 2, p. 443465, 2009.

STRIEGL, R.G. Diffusional limits to the consumption of atmospheric methane by soils. Chemosphere, v. 26, n. 1-4 p. 715-720, 1993.

TELLES, E.C.C.; CAMARGO, P.B.; MARTINELLI, L.A.; COSTA, A.S.; SANTOS, J.; HIGUCHI, N.; OLIVEIRA, R.C. Influence of soil texture on carbon dynamics and storage potential in tropical Forest soils of Amazonia. Global Biogeochemical Cycles, v. 17, n. 2, p. 1029-2002, 2003.

VIGANO, I.; HOLZINGER, R.; VAN WEELDEN, H.; KEPPLER, F.; MCLEOD, A.; RÖCKMANN, T. Effect of UV radiation and temperature on the emission of methane from plant biomass and structural components. Biogeosciences Discuss, v. 5, ed. 3, p. 243-270, 2008.

WMO - World Meteorological Organization. Greenhouse Gas Bulletin (GHG Bulletin): The State of Greenhouse Gases in the Atmosphere Based on Global Observations though 2011. n. 8, p. 1-4, 2012.

WOFSY, S.C.; HARRISS, R.C.; KAPLAN, W.A. Carbon dioxide in the atmosphere over the Amazon basin. v. 93, ed. 2D p. 1377-1387, 1988.

WUEBBLES, D.J.; HAYHOE, K. Atmospheric methane and global change. Earth Sciense Reviews, v. 52, ed. 3-4, p. $177-210,2002$.

License information: This is an open-access article distributed under the terms of the Creative Commons Attribution License (type CC-BY), which permits unrestricted use, distribution and reproduction in any medium, provided the original article is properly cited. 